\section{Back to Shakespeare}

\section{Frank Kermode: Shakespeare's Language \\ (London: Allen Lane \\ The Penguin Press, 2000)}

The past couple of years have seen the apparition of several heavyweight books about Shakespeare by heavyweight senior contestants in the literary critical arena. After Harold Bloom, who has elaborated his vision of Shakespeare as the inventor of the human in well over seven hundred pages, and Helen Vendler, who at the beginning of her book made the statement - once commonplace but now apparently in need of reiteration - that she does not "regard as literary criticism any set of remarks about a poem which would be equally true of its paraphrasable content," Frank Kermode has also published what he had to say about Shakespeare at the turn of the century.

Bloom, Vendler, and Kermode, three scholar-critics of radically different persuasions and intellectual styles, have at least one thing in common among them: they all remained untouched by the critical and theoretical fashions of the last quarter of the $20^{\text {th }}$ century. But while Bloom and Vendler chose rather to ignore whatever their more trend-conscious colleagues may have produced over these years, and stubbornly proceeded with their own, prophetic (Bloom) or aesthetic-analytic (Vendler) modes of reading, Kermode has critically engaged with the emergent and dominant tendencies, actively promoting the assimilation of continental work to the practice of English and American criticism. A stunningly versatile critic, he started his career as a Renaissance scholar, with a book on English Pastoral Poetry from the Beginnings to Marvell, ${ }^{1}$ followed by an edition of The Tempest, ${ }^{2}$ partly an offshoot of the former. He also wrote about Donne and Milton (striving to reverse Milton's fortunes after the unhappy neglect over the mid-century), but then abstained from Renaissance studies for decades. This period saw the rise, most importantly, of New Historicism, described by Kermode in a recent review as "a way, or a bundle of ways, of writing about literary history which incorporates insights provided by other intellectual disciplines, refuses to isolate literature from other forms of discourse, and assumes that the entire culture, including many aspects of it generally overiooked by conventionai history - for instance, anecdotes concerning the lives and behaviour of ordinary people - can be regarded as text, with all of its parts somehow interrelated." What annoys Kermode in this new koine of Renaissance Studies is that it "excludes attempts to differentiate between writing that was once re- 
garded as literary, of aesthetic value, and all other contemporary documents" ${ }^{4}$ - in short, that it fails to recognise literature for what, at least according to most non-academic readers and to less trendy critics, it is. As he puts it, writing about the Collected Works of Queen Elizabeth I, the trend now is to "believe that the 'rapidly changing intellectual developments of the past twenty-five years' in a climate of 'revised assumptions about literary value' have shown there is no need to distinguish between [occasional and political] writing and writing formerly thought to have higher aesthetic value. It seems as pointless to argue about this as it would be to dispute an argument that the sole value of Beethoven's last quartets, like that of all other artistic productions of their time, must be sought solely in the political and social conditions of Vienna in the 1820 s."

Some of the formulations in the short Preface to Shakespeare's Language are no less straightforward. Kermode "particularly dislikes" two modern attitudes to Shakespeare: one "that maintains that the reputation of Shakespeare is fraudulent, the result of an eighteenth century nationalist or imperialist plot. A related notion," he goes on, "almost equally as presumptuous, is that to make sense of Shakespeare we need first to see the plays as involved in the political discourse of his day to a degree that has only now become intelligible" (viii). With such broad and hostile generalisations, the sometime negotiator between modern theory and more traditional modes of reading now joins the ranks of conservative antitheoretical Shakespeareans - a tendency which found its definitive and bulky, if disappointingly superficial, formulation in Brian Vickers's Appropriating Shakespeare half a decade ago. But Kermode's interest lies not in New Historicismbashing. His most important complaint, underlying all the rest, is that such trendy scholarly work on Shakespeare (as well as on any other author) fails to address itself to, and in any case to be accessible to, a non-professional audience. Politically motivated writing on Shakespeare, while still claiming for itself a significance extending well beyond the groves of academe, moved way beyond the ken of the "general reader," or, on the rare occasion when such criticism tries to make its voice heard in wider circles, it really tends to make statements which are adequately parodied by Kermode's summary treatment. The academic study of literature has become increasingly isolated from the world of everyday nonprofessional reading of books - for pleasure, recreation, entertainment, or escape.

Kermode is widely respected as one of the most important critics of our 
age, and the present book aims to be, first and foremost, a "critical" one - a term that will be echoing throughout the present sketch. ${ }^{6}$ Shakespeare's Language is a critical book in that it is evaluative and appreciative (much contemporary "literary criticism" refuses to be critical in this sense, which is why I avoided using the term so far) and also undertaking the traditional task of mediating between the writing and its audience. Implicit in Kermode's call for resistance to the radical historicisation of literary value thus there is a call for renewed critical attention: for comparison, evaluation, and judgement of quality, and (in perfect accord with Vendler's creed and practice) also for inquiry into the linguistic groundwork underpinning them - a responsibility, Kermode emphasises, much modern criticism chooses to evade, and one which Shakespeare's Language undertakes.

In the two parts the book is divided into, Kermode offers a very strong critical reading of Shakespeare's career. In the first, much shorter section, he surveys the dramatic output of the early years, and then, in Part II, devotes a chapter to each one of the later plays, from Julius Caesar to The Two Noble Kinsmen. (A chapter each, that is, except All is Well, the treatment of which is included in, or subordinated to, that of Measure for Measure, and Herry VIII and The Two Noble Kinsmen, which are dealt with together.) The twofold structure is a manifestation of Kermode's perception of the shape of Shakespeare's career as a writer. The turning point more or less coincides with the move of Shakespeare's company to the newly built Globe, but is described by Kermode as more of a poetical than an external transformation. The years around 1600 saw an important shift from earlier acting styles to "personation," a new style based not on set types and formal stage rhetoric, but on verbal representation of individuality, matched by, and made possible by a verbal style which should be seen as Shakespeare's singular achievement $(6,244)$.

The early plays are full of formal orations (27) - "an old-style affectedness, drawing attention to its own unnaturalness" (36) - a highly wrought style characterised by the neatly deployed ornaments of stichomythia, anaphora, by detailed analogies system atically worked our, etc. But over the last years of the $16^{\text {th }}$ century, Shakespeare's plays betray an increasing sense that the decorative old manner came to be felt as false and unreal (46), a perception followed by the emeregence of the new, mature dramatic poetry we now see as characteristicaliy Shakespearean. This new mode has its own particular depths, which at the same time involve 
particular difficulties: it is distinguished by a "toughening up of the language, accompanied by a new freedom of metaphor and allusion and a rougher handling of the pentameter" (17), difficult sentences breaking off in mid-line (144), along with sudden "alternations of compression and expansion" adding up to an underlying Shakespearean rhythm (150) - in short, a style that shows "more concern with the kind of art that conceals art" (19), one in which "the mature Shakespeare expresses the wavering complexity of emotionally agitated thought" (150). Such imitation of "the actual movement of thought in a character's mind" (245) results in "stubborn repetition, free association, violent ellipses; in short, a prevailing ruggedness in tone" (246) - features that yield their most satisfactory results in Coriolanus, the play Kermode sees as Shakespeare's ultimate masterpiece in terms of his handling of the medium.

The structure of Shakespeare's Language reflects the contrast between early pieces and the "unpredictable profundity" of the mature work. Early plays like Titus and the chronicles are in a perceptive section compared to the youthful and ephemeral music of Mozart's, seen "as early, undeveloped preparations, in themselves not particularly significant, for some highly original achievements of the composer's maturity" (12) - in the case of Shake- speare, for the period expanding from Hamlet to Coriolanus, followed by the late plays, characterised by "a kind of reticence that might, in relation to that speech in Titus Andronicus [ Marcus's speech in II.iv], be thought close to silence" (13). Such a sketch may under normal circumstances sound little more than commonplace, but - somewhat oddly - in the case of Shakespeare, the best known and most studied literary author of the West, a clear account of the shape of the oeuvre is felt a welcome addition to libraries of critical work. Shakespeare has become so great and so venerable (and venerated) that clear-sighted evaluation of the relative merits and faults of the various parts of the corpus has become a rarity. This is why one must greet an enterprise which, following in the wake of Johnson and Eliot, reinserts Shakespeare into the field of critical enquiry.

The critical, rather than scholarly or academic tendency of Shakespeare's Language is also manifest in the musical groundwork of its language - we read about the tunes and themes of the verse, about certain figures providing a ground bass, about sudden switches into a new key, etc. The phraseology is motivated by Kermode's general attitude, which is appreciative rather than interpretive. Putting it very bluntly, it aims to follow the experience of Shakespearean verse, rather than trying to 
tell what it tells us. It points out special beauties, difficulties and intricacies, with the ultimate aim of facilitating appreciation, rather than settling for some reading or using the plays as testcases or indeed battlefields for the analysis or contestation of some intellectual, political or historical issue. Kermode performs critical readings as opposed interpretations of the plays.

Like the career, so the plays also seem to have a tendency to fall into halves in Kermode's book. The second half of Measure for Measure, of Troilus, Hamlet, Julius Caesar or Macbeth seem not worth to be discussed in Shakespeare's Language. Even with plays that receive a more even-handed treatment, Kermode is always more elaborate on early than later scenes - this might be a function of his interpretive interest in identifying the main themes and tunes of a play rather than following their elaboration all the way through - presumably, once alerted to them, any sensitive reader will be able to do that. Furthermore, according to Kermode, Shakespeare's opening scenes, unlike latter bits of some of the plays, tend always to be "carefully excogitated" (166). But underlying Kermode's emphasis on the initial scenes and the difference in the treatment of the rest might be taken to suggest a distinction between plays like Lear, Antony and Cleopatra, Coriolanus or, with certain qualifications, The Winter's Tale and The Tempest on the one hand, and plays where critical interest dwindles after the first two or three acts, like in the case of Troilus or Julius Caesar. Kermode's preferences seem to identify the group of the most "mature" plays, characterised by the most sustained intensity, the examples of what Kermode considers as the best of Shakespeare's high-pressure syntax and semantics, adequate with dramatic character and situation - an essential criterion for him.

As in Shakespeare's Language Kermode is interested not so much in churning out "readings," but in giving an account of, and enticement to, reading, he also readily admits failure and puzzlement. In his analyses, complication is at best not an obstacle in the way of the appreciation of poetic qualities, but something to be appreciated in itself as a poetic quality - one, which, nevertheless, occasionally forces the critic to revert to the heresy of paraphrase by way of explaining the difficulties. As Kermode puts it, "Given this new way of representing turbulent thinking, so different from plainly formulated thought, set out clearly and reinforced by elaborately illustrative and copious comparisons [characteristic of the formal rhetoric of the histories and early comedies], obscurities will inevitably plague commentators as well 
as audiences" (16). These obscurities, inherent to such style, at times leave the reader or audience to see the point without properly speaking "understanding" the sentence - which at first appears as a characteristic and powerful poetic device, but then, increasingly, also as a dangerous one.

The traditional aim of literary interpretation is to clear away such difficulties. But a theatre audience couldn't possibly have relied on commentaries, glosses and the desperate measures of conjectural emendation. As Kermode points out, following, catching the drift, rather than fully understanding is sometimes the only option, occasionally even after repeated readings aided by explanatory notes and encyclopaedias. This admittance to a failure to understand is, at first sight perhaps paradoxically, closely related not only to taking into account the opportunities and limitations of the "general reader" but also to a difference between the interpretive habits of Kermode and Empson, Kermode's single most important point of reference, a critic with whom he shares an interest in Shakespeare's semantic or lexical obsessions as well as in the poetic importance of ambiguity. Unlike Empson (whose most interesting work now reads as socalled deconstructive literary criticism, though without the jargon derived from Derrida), however, Kermode (attentive as he is to linguistic ambiguity and semantic oscillation) insists on the necessity of setting certain limits to interpretation. Plays are there to be experienced by theatre audiences, or perhaps, morc recently, by readers in their armchairs, and in that process, difficulties and obscurities will inevitably be glossed over. If something is ultimately obscure, this should be admitted and, after a certain amount of effort spent on its explanation, left as it is, "or explanation gets lost in mere noise" (155).

Kermode's chief interest is in the dramatic functionality and adequacy of the verse style. Obscurity and difficulty are often suggestive ways of representing "the wavering complexity of emotionally agitated thought" - Shakespeare mature style is, among others, inflected by a new use of soliloquy, which no longer just conveys information to the audience, but also serves as the medium of considering larger issues, while at the same time showing a mind at work (115). This new type of monologue is itself a function of the new notion of an inaccessible life within, first emerging in plays like Richard II, Julius Caesar and Hamlet. For Kermode, Shakespeare is really at his best in these tragic verse monologues, characterised by a certain energy and "flurries of oblique associations." But obliqueness at times seems 
disfunctional, the result of verbal habit and unnecessary showing of linguistic muscles - as in Cymbeline, for example. On the other hand, the intense experimentation of the transitional period of Troilus, All's Well, and Measure for Measure lead to large-scale transformations as well as local failures - these "problem plays" "seem to present not only distinctively ethical problems but peculiar difficulties of a poetic kind" (126). Now if the development of Shakespeare's career first takes Kermode uphill from Titus to Coriolanus, from that play on the oeuvre seems to go somewhat downhill with its overly obscure formulations. Although The Tempest and The Winter's Tale, two unquestionable masterpieces, appear as exceptions from this trend, after a discussion of Henry VIII and The Two Noble Kinsmen, the book ends on a note of doubt regarding the last pieces, and its general drift is that Shakespeare was really placing too much pressure on the audience by now: "Did he overestimate their endurance, and ours; did he perhaps even exaggerate his own?" (312).

If the book insists on an early-late (or, perhaps less clearly, earlyhigh/mature-late) distinction, it also implies some others. The most obvious one of these is Kermode's preference for the tragedies over the comedies. The Comedy of Errors is even left out of a survey otherwise devoting at least a paragraph or two to each play. All the plays he finds problems with in Part II - the section that starts with Julius Cae. $s a r-a r e$ comic, or at least partly comic, like All's Well, the Two Gents, or the tragi-comedy of Cymbeline, while the discussion of Measure for Measure does not extend beyond the point it departs from a tragic into a tragicomic direction. Similarly, one might argue that $A s$ You Like It, though admittedly a Globe play is placed in the first section, where most comedies are anyway, because as a less perfect and comic piece it would have watered down the intensity of the mature period. While Kermode's reservations no doubt also have other reasons, such partiality for one genre over another is conspicuous.

What Kermode pays close attention to as the high Shakespearean manner is (in a fashion perhaps high Bradleyan, but certainly high modernist) characteristically tragic. But it also tends to be poetic, i.e. written in verse - in spite of some illuminating points he has to make about the prose of these middle years. Kermode is excellent on the motivations behind the choice of prose or verse at particular points, showing the question a lot more complicated and significant than we tend to assume but for comments on the prose itself, we are directed to Brian Vickers's 1968 The Artistry of Shakespeare's Prose. A 
striking result of these two delimitations of what counts as quintessentially Shakespearean (i.e. a writing that is tragic and in verse) is that the book has surprisingly little to say about Falstaff, especially for a book called Shake. speare's Language. Or has Falstaff's linguistic exuberance lost its appeal for modern audiences? The most powerful Falstaff of the post-war years, that of Orson Welles in Chimes at Midnight, for example, is perhaps memorable for other things - for his vulnerability and melancholy, and first and foremost for his grotesque body: his verbality is, oddly, not so much a linguistic, but a physical aspect of his personality, memorable as an eruption of sheer garrulousness.

It is in the tragic verse monologues of the Globe years that Shakespeare, from the late-nineties on, "began to use a word or group of words as a central element, almost a subject of exploration, in his verse" (59). This "habit of serious word-play," as Kermode describes it, results in verbal patterns connected to, but different from, the thematic centres of plays, and their identification in Shakespeare's Language often provides the hinges for fullfledged interpretations. Kermode's discussions of such words - "doting" in A Midsummernight's Dream, "gent(i)le" in The Merchant, "opinion" in Troilus, "nothing" and "seeing" in Lear, "honest" in Othello, "world" in Antony $\&$ Cleopatra, may seem his most explicit form of indebtedness to Empson. But his analyses only reach the complexity of Empson's essays on such "complex words" once: and that is in a piece not about a semantic, but a rhetorical structure, in the superb fulllength reading of Hamlet organised around the use of hendiadys (the kind of trope based on the splitting of an expression into two, as in law and order, house and home) and other doubling devices, from slings and arrows through showing "the body of time his form and pressure" to "the whips and scorns of time," which set the unmistakable tune of the verse of the play, providing "a sort of ground bass that sounds everywhere" (106). The chapter on Hamlet, perhaps the best in the book, is a rhetorical tour de force connecting (to be faithful to the spirit of the text as well as the chapter discussing it) most aspects and elements of the play through the mustering up and discussion of alternatives and bifurcations, of verbal and other doublings.

Apart from such grand verbal themes, Kermode also shows an interest in the "little language" of some of the plays, the use of a set of words to give undercurrents of sense to the dramatic dialogue. But towards the end of the book, the implicit definition of what counts as a problem of "language" 
changes somewhat. In Kermode's discussion of the romances, the structures of the plot come to the foreground of interest, and among these, one in particular: recognition features quite prominently. This is perhaps the point where it most clearly shows how Shakespeare's Language goes beyond attention to style, rhetoric and semantic complexity. By the end of the book, the term "Shakespeare's language" seems to become coterminous with "the poetics of Shakespeare's plays" and recognition, or anagnorisis, surely is a poetic structure already dealt with in Aristotle's Poetics. But even so, its rather careful consideration feels a sidetrack, a direction taken to complement the relatively little the book has to say about the late plays otherwise - as if to make the coverage and the distribution of material over the whole work more even. A noble effort, and perhaps one of the reasons why Shakespeare's Language reads less like a sequence of chapters or papers, more like a series of lectures on Shakespeare's plays - it is, in fact, an addition to the great tradition lectures on Shakespeare, like those of Coleridge, Bradley or Auden. Like lectures meant for oral delivery, it is a text with digressions, repetitions and explanations of difficult passages. They feature introductory passages on the date, texts and topicality of the given play, and then moves on to reading selected excerpts embedded in a sketch of the development of major elements of themes and of the plot - also providing, as Kermode intends it, a sort of general introduction for the general reader. And the fate of the book, it now seems to me, will be very much bound up with the fate of that elusive creature.

ANDRÁS KISÉRY

\section{NOTES}

${ }^{1}$ Frank Kermode. English Pastoral Poetry from the Beginnings to Marvell. London: Harrap, 1952.

${ }^{2}$ William Shakespeare. The Tempest. Ed. Frank Kermode. London: Methuen, 1954 (The Arden Shakespeare).

${ }^{3}$ Frank Kermode. "Art among the ruins." NYRB July 5, 2001.

${ }^{4}$ Frank Kermode. "Writing about Shakespeare." $L R B$ December 9, 1999. (A condensed version of the argument of the book, taken from its introduction and the chapter on Coriolanus, itself something like a summary of the whole.)

${ }^{5}$ Frank Kermode. "But could she cook?" NYRB April 12, 2001.

${ }^{6} \mathrm{Cf}$. Sándor Radnóti. "In defense of interpretation." Arcadia, 2000. 